\title{
DESEMPENHO NAS DISCIPLINAS DE MATEMÁTICA, ESTATÍSTICA E MÉTODOS QUANTITATIVOS NO CURSO DE CIÊNCIAS CONTÁBEIS
}

\section{PERFORMANCE IN MATHEMATICS, STATISTICS AND QUANTITATIVE METHODS IN ACCOUNTING SCIENCES COURSE}

\section{RESUMO}

O desempenho acadêmico é amplamente considerado um dos principais preditores do sucesso de uma universidade, principalmente quando se observa disciplinas que são de suma importância no processo de formação, como Matemática, Estatística e Métodos Quantitativos. Nessa linha, a presente pesquisa objetivou identificar a relação dos fatores relacionados às características individuais e atitudes no desempenho acadêmico nas disciplinas de Matemática, Estatística e Métodos Quantitativos, ministradas no curso de Ciências Contábeis da Universidade Federal de Uberlândia, campus Pontal. A pesquisa foi realizada por meio de levantamento, com a aplicação de questionários impressos, sendo obtidas 75 respostas válidas. A análise dos dados foi desenvolvida considerando a estimação de modelo de regressão logística, para qual foi utilizado o software Stata. Por meio do modelo de regressão estimado, constatou-se que os elementos referentes a idade e estado civil estão relacionados à maior probabilidade de reprovação, ou seja, menor desempenho, enquanto a jornada de trabalho, frequência, participação nas aulas e dedicação tempo para estudos extraclasse, indicam chance de obtenção de maior desempenho ou não reprovação. Esses achados contribuem com o fluxo de pesquisa que busca explicar os fatores determinantes do desempenho acadêmico, bem como para o contexto da prática no ambiente escolar na busca pela adoção de estratégias que alavanquem o desempenho.

Palavras chave: Desempenho acadêmico, Matemática, Estatística, Métodos Quantitativos.

\begin{abstract}
Academic performance is widely considered one of the main predictors of a university's success, especially when observing subjects that are of paramount importance in the training process, such as Mathematics, Statistics and Quantitative Methods. In this line, this research aimed to identify the relationship of factors related to individual characteristics and attitudes in academic performance in the disciplines of Mathematics, Statistics and Quantitative Methods, taught in the Accounting Sciences course at the Federal University of Uberlândia, campus Pontal. The research was carried out through a survey, with the application of printed questionnaires, obtaining 75 valid answers. The data analysis was developed considering the estimation of the logistic regression model, for which the Stata software was used. Through the estimated regression model, it was found that the elements referring to age and marital status are related to a higher probability of failure, that is, lower performance, while the workday, frequency, participation in classes and dedication time to extra-class studies indicate chance of obtaining higher performance or failing. These findings contribute to the flow of research that seeks to explain the determining factors of academic performance, as well as to the context of practice in the school environment in the search for the adoption of strategies that leverage performance.
\end{abstract}

Keywords: Academic performance, Mathematics, Statistics, Quantitative Methods.
Renata Mendes de Oliveira

Doutorando em Contabilidade pela Universidade Federal de Santa Catarina Mestre em Contabilidade pela Universidade Federal do Paraná. Graduada em Ciências Contábeis pela Universidade Federal de Uberlândia. Docente do curso de Ciências Contábeis na Universidade Federal de Uberlândia - Campus Pontal. Contato: Rua Vinte, 1600, Bairro Tupã, Ituiutaba, MG, CEP: 38.304-402. E-mail: remendes.itba@ gmail.com

\section{Regiane Aparecida da Costa} Graduada em Ciências Contábeis pela Universidade Federal de Uberlândia. Assistente Financeiro na Protec Produtos Agrícolas. Contato: Rua Vinte, 1600, Bairro Tupã, Ituiutaba, MG, CEP: 38.304-402 E-mail: regianneacosta@hotmail.com 


\section{INTRODUÇÃO}

No decorrer do processo de formação, o discente do curso de Ciências Contábeis deve ser capaz, dentre outras coisas, de perceber o conhecimento ao seu redor nas diferentes áreas, dentre as quais está a matemática, sendo os métodos quantitativos um auxiliador nesse contexto (Cardozo, 2006). Destaca-se que os métodos quantitativos são relevantes, uma vez que abordam conteúdos que estão associados a aplicações no universo profissional, bem como oferecem referências à pesquisa cientifica (Costa, Lopes Júnior, Lemos \& Lôbo, 2009).

Diferentes pesquisas abordam sobre a importância dos conteúdos das disciplinas de Matemática, Estatística e Métodos Quantitativos, que se juntam às demais necessárias para formação básica no curso de Ciências Contábeis, tais como Administração, Economia e Direito (Boarin, 2003, Cardozo, 2006; Limongi, Pfitscher, Freitas, Krüger \& Soares, 2012; Alves, Farias \& Farias, 2015). Pondera-se a relevância de se ter a interação entre as diversas disciplinas ofertadas no curso, na busca por propiciar conhecimento de forma integral, que sejam pertinentes às necessidades dos usuários da contabilidade de forma geral (Fiorentin \& Domingues, 2012).

Apesar de oferecerem conteúdos relevantes, existe uma grande dificuldade relacionada às disciplinas de Matemática, Estatística e Métodos Quantitativos, o que por vezes pode comprometer o bom desempenho dos discentes (Cardozo, 2006). O desempenho sempre foi assunto em todos os sistemas e programas educacionais por proporcionar aprimoramento e aperfeiçoamento das técnicas de ensino e das políticas educacionais (Miranda, Lemos, Oliveira \& Ferreira, 2015). O desempenho acadêmico de um discente, independentemente do grau de escolaridade almejado ou do curso escolhido, pode sofrer influência de alguns determinantes.

$\mathrm{Na}$ área de negócios e contabilidade, pesquisas evidenciaram que o desempenho dos discentes pode ser influenciado por elementos relacionados às características pessoais, psicológicas, questões de natureza socioeconômica ou ainda decorrente do ambiente (Al-Twaijry, 2010; Abdullah, 2011; Santos, 2012; Seow, Pan \& Tay, 2014; Jansen \& Villiers, 2016; Kumar, 2018). Além disso, o desempenho discente pode ser relacionado às características que envolvem os docentes, tais como estratégias e métodos de ensino utilizados e experiência profissional, ou ainda características às instituições de ensino, como qualidade do acervo bibliográfico, infraestrutura da sala de aula e quantidade de recursos tecnológicos (Miranda et al., 2015).

Diante do exposto, a presente pesquisa apresentou como objetivo identificar a relação dos fatores relacionados às características individuais e atitudes no desempenho acadêmico nas disciplinas de Matemática, Estatística e Métodos Quantitativos, ministradas no curso de Ciências Contábeis da Universidade Federal de Uberlândia, campus Pontal.

Em linhas gerais, a presente pesquisa apresenta contribuições de natureza teórica uma vez que acrescenta aos estudos já desenvolvidos no âmbito da contabilidade que abordaram sobre a temática do desempenho acadêmico (Araújo, Camargos, Camargos \& Dias, 2013; Miranda et al., 2015; Rodrigues, Resende, Miranda \& Pereira, 2016; Amaro \& Beuren, 2018).

A discussão sobre disciplinas como Métodos Quantitativos no ensino em cursos de contabilidade, requer a atenção da instituição como um todo, envolvendo coordenação, professores e discentes, na busca por compreender a percepção dos envolvidos no processo em relação à disciplina, bem como o uso que se faz (Cardozo, 2006). Diante disso, tem-se evidenciada a importância, no âmbito da prática educacional, de se conhecer os fatores determinantes para o bom desempenho em disciplinas que consideram aspectos quantitativos.

O interesse no impacto que os conhecimentos em Matemática e Estatística têm no desempenho do discente de Ciências Contábeis é importante antes de seu encaminhamento definitivo para o mercado profissional (Costa, Machado \& Lima Neto, 2014). Nessa perspectiva, os conteúdos relacionados aos Métodos Quantitativos representam uma das faces da Ciência Contábil, por isso, o desempenho e o rendimento obtido pelos discentes deveriam ser satisfatórios, visto que a análise de dados apresentados pelas empresas é realizada por meio de métodos e ferramentas disponibilizadas por esta área do conhecimento (Alves et al., 2015).

Dessa forma, espera-se que a presente pesquisa possa contribuir ao evidenciar fatores determinantes para o bom desempenho, de modo a auxiliar diretores, coordenadores e docentes no planejamento de estratégias pedagógicas mais adequadas às necessidades dos discentes. Assim, pode-se trabalhar possíveis falhas para que o desempenho se torne satisfatório não só a título de formação, como também para a atuação profissional. 


\section{FUNDAMENTAÇÃO TEÓRICA}

\subsection{Formação do Contador e a importância das disciplinas de Matemática, Estatística e Mé- todos Quantitativos}

A Organização das Nações Unidas (ONU) emitiu, em 2003, o Plano de Estudos Mundial para a Formação de Contadores Profissionais, por meio do International Standarts of Accounting and Reporting/United Nations Conference on Trade and Development (ISAR/UNCTAD), que determinou a adoção do termo "Métodos Quantitativos" no Currículo do Contador Global Financeira (UNCTAD, 2003). Essa terminologia reúne as disciplinas Matemática, Estatística e Matemática Financeira (UNCTAD, 2003).

Em conformidade com o Plano Mundial, o Ministério da Educação instituiu as Diretrizes Curriculares Nacionais para o curso de graduação em Ciências Contábeis com a promulgação da Resolução CNE/CES nº 10/2004, evidenciando, em seu artigo $5^{\circ}$, os campos de formação, básica, profissional e teórico-prático, como pode ser observado na Figura 1.

\begin{tabular}{|l|l|l|}
\hline \multicolumn{1}{|c|}{ Formação Básica } & \multicolumn{1}{|c|}{ Formação Profissional } & \multicolumn{1}{c|}{ Formação Teórico-Prático } \\
\hline $\begin{array}{l}\text { Estudos relacionados com outras áreas do } \\
\text { conhecimento, sobretudo Administração, } \\
\text { Economia, Direito, Métodos Quantitativos, } \\
\text { Matemática e Estatística. }\end{array}$ & $\begin{array}{l}\text { Estudos específicos atinentes às Teorias } \\
\text { da Contabilidade, incluindo as noções das } \\
\text { atividades atuariais e de quantificações } \\
\text { de informações financeiras, patrimoniais, } \\
\text { governamentais e não-governamentais, de } \\
\text { auditorias, perícias, arbitragens e contro- } \\
\text { ladoria, com suas aplicações peculiares ao } \\
\text { setor público e privado. }\end{array}$ & $\begin{array}{l}\text { Estapervisionado, Ativ- } \\
\text { pendentes, Conteúdos Optativos, Prática } \\
\text { softio de Informática utilizando }\end{array}$ \\
\hline
\end{tabular}

Figura 1. Conteúdo para cursos de graduação em Ciências Contábeis no Brasil

Fonte: Resolução CNE/CES nº 10/2004

Nota-se que tanto o Plano de Estudos Mundial para a Formação de Contadores Profissionais, quanto a Resolução CNE/CES n ${ }^{\circ}$ 10/2004, evidenciam a necessidade de que sejam oferecidos, nos cursos de Ciências Contábeis, conteúdos relacionados à Matemática, Estatística, e Métodos Quantitativos, como elementos inerentes a formação básica essencial. Nessa linha, pondera-se que a matemática, ofertada nos cursos de graduação em Ciências Contábeis, acaba por oferecer base para a compreensão em relação aos conteúdos trabalhados em disciplinas como Estatística, Contabilidade de Custos, Contabilidade Gerencial, Contabilidade Geral, Análise de Balanço (Silva \& Machado, 2004).

No campo do preparo para atuação prática, o uso de métodos quantitativos fornece subsídios ao auxiliar no desenvolvimento de conhecimentos necessário para predição e retroalimentação de informações contábeis (Alves et al., 2015). Vale destacar que a predição e retroalimentação estão entre as características relevantes necessárias para a obtenção de informações de qualidade no processo de tomada de decisão (CPC 00 - R1, 2011).

A Teoria Matemática, associada aos conhecimentos relacionados às informações patrimoniais fornecidos pela contabilidade, torna possível a geração de diferentes cenários que permitem maior previsibilidade (Silva \& Machado, 2004). Nessa linha, o uso das ferramentas quantitativas pode ser tido como um importante elemento no processo de análise de dados, enfatizando a função gerencial do profissional contábil (Stringhini, 2014).

Stringhini (2014) retrata algumas possíveis aplicações de métodos quantitativos em diversas áreas da contabilidade. Ao observar a Figura 2, fica evidente a importância do aprendizado e aplicação dos métodos quantitativos na formação discente, bem como na atuação no mercado profissional, uma vez que que são muitas as funcionalidades e aplicações dos conteúdos oferecidos. 


\begin{tabular}{|c|c|c|}
\hline Área & Aplicação & Técnica \\
\hline Análise de Balanços & $\begin{array}{l}\text { Comparação entre Índices Padrão da Empre- } \\
\text { sa e do Mercado Comparação de Índices com } \\
\text { o Ramo de Atividade Modelos de Avaliação } \\
\text { de Índices Conjuntos com Ponderação Com- } \\
\text { paração entre índices de } 2 \text { grupos de empre- } \\
\text { sas Comparação de PCT e LCA Projeção de } \\
\text { Contas do Balanço Previsão de Insolvência } \\
\text { com o uso de Indicadores Contábeis }\end{array}$ & $\begin{array}{l}\text { Quartis, Decis ou Percentis e Mediana Quartis, } \\
\text { Decis ou Percentis e Mediana Distribuição Normal } \\
\text { Média Aritmética Ponderada ou Regressão Linear } \\
\text { Teste t de student ou qui-quadrado Coeficiente } \\
\text { de Correlação Regressão Linear Análise Fatorial } \\
\text { e Discriminante Média Aritmética Simples e Pon- } \\
\text { derada, Testes t e z, Probabilidade Simples - Teo- } \\
\text { rema de Bayes e Regressão e Correlação Linear }\end{array}$ \\
\hline Avaliação dos Estoques & $\begin{array}{l}\text { Cálculo do valor unitário de itens do estoque } \\
\text { pelo método Custo Médio Ponderado }\end{array}$ & Média Aritmética Ponderada \\
\hline Auditoria & $\begin{array}{l}\text { Amostragem Estatística e não Estatística ou } \\
\text { Probabilística e não Probabilística em Testes } \\
\text { de Controle ou Substantivos }\end{array}$ & $\begin{array}{l}\text { Métodos de Seleção de Amostra e Intervalo de } \\
\text { Confiança Determinação do tamanho da amostra } \\
\text { para estimar a média e a proporção }\end{array}$ \\
\hline Contabilidade Atuarial & $\begin{array}{l}\text { Cálculo de Taxa Pura e Prêmio Puro Cálculo } \\
\text { da Probabilidade de Sobrevivência e de Mor- } \\
\text { talidade no Cálculo de Prêmios de Seguros e } \\
\text { de Capitalização }\end{array}$ & $\begin{array}{l}\text { Distribuição Normal e Intervalo de Confiança Cál- } \\
\text { culo das Probabilidades }\end{array}$ \\
\hline Contabilidade Gerencial & $\begin{array}{l}\text { Modelo de Precificação de um Ativo com Ris- } \\
\text { co - CAPM (Capital Asset Pricing Model) Lu- } \\
\text { cro Limpo (CSR) Tratamento Econométrico } \\
\text { (modelo de Ohlson - 1995) - Relação Lucro } \\
\text { Líquido x Patrimônio Líquido em conjunto ou } \\
\text { Isolados }\end{array}$ & $\begin{array}{l}\text { Covariância, Variância, Correlação, Regressão } \\
\text { Linear Probabilidade Estocástica, Regressão Lin- } \\
\text { ear Coeficiente de Determinação e Regressão } \\
\text { Linear }\end{array}$ \\
\hline Controle Estatístico de Qualidade & $\begin{array}{l}\text { Avaliação da Variação entre Valores dentro } \\
\text { de uma determinada conta contábil Verifi- } \\
\text { cação de valores com distorção significativa }\end{array}$ & $\begin{array}{l}\text { Teoria do Limite Central, Distribuição Normal e de } \\
\text { Student Intervalo de Confiança e Teste de Hipó- } \\
\text { tese }\end{array}$ \\
\hline Contabilidade de Custos & $\begin{array}{l}\text { Modelos Comparativos (ex: Gastos Publici- } \\
\text { dade x Vendas) Funções Lineares de Rateio } \\
\text { de Custos Indiretos Relação Quantidade x } \\
\text { Custos x Receita x Lucro Análise da Curva de } \\
\text { Aprendizagem }\end{array}$ & $\begin{array}{l}\text { Regressão e Correlação Linear Regressão e Cor- } \\
\text { relação Linear Regressão e Correlação Linear Re- } \\
\text { gressão e Correlação Linear }\end{array}$ \\
\hline
\end{tabular}

Figura 2. Possíveis aplicações de métodos quantitativos em contabilidade Fonte: Stringhini (2016, p. 4)

Considerando o exposto nessa unidade, percebe-se a importância de os graduandos em Ciências Contábeis obterem um bom desempenho acadêmico em disciplinas de cunho quantitativo, uma vez que, durante o exercício profissional, os mesmos terão a necessidade de recorrerem aos conteúdos aprendidos em tais disciplinas para que consigam realizar o seu trabalho com maior efetividade.

\subsection{Desempenho Acadêmico}

O desempenho acadêmico é a mensuração do processo de ensino-aprendizagem, por meio de conceitos ou avaliações numéricas, que permite a avaliação discente, ofertando indicativos do sucesso do discente, quanto ao aproveitamento do conteúdo apresentado, ou do insucesso em casos de reprovação (Munhoz, 2004). Ainda conforme o autor, o desempenho acadêmico está associado a três fatores, a inteligência (dimensão das habilidades da pessoa), habilidade (potencial para a realização da atividade) e a competência (nível de cumprimento das atividades).

O desempenho no ambiente acadêmico não é útil apenas para avaliação do discentes ao longo de sua jornada acadêmica, mas também serve para avaliar os docentes e as Instituições de Ensino Superior (Silva, Oliveira, Rogers \& Miranda, 2015). Além disso, salienta-se que o desempenho acadêmico é considerado um importante preditor para o desempenho no trabalho, atuando como indicativo de habilidades cognitivas e motivacionais (Imose \& Barber, 2015).

Ao considerar o insucesso acadêmico no ensino superior, Martins (2004) afirmou que esse está intimamente ligado ao insucesso no ensino básico e secundário e as disciplinas que envolvem principalmente a matemática, onde se observa a maior dificuldade no processo de aprendizagem. Para o autor, insucesso significa não atingir metas ou não ser aprovado ao final de um período temporal estabelecido, como um semestre ou ciclo.

A mensuração do desempenho acadêmico por meio de notas obtidas em trabalhos, provas e atividades diversas, não é a melhor opção, pois indica apenas o resultado final e não leva em consideração todo o processo de aprendizagem (Araújo et al., 2013). Trata-se de um dado frágil, à medida que podem ser utilizados artifícios para maximização, de modo a não refletir o real desempenho. 
Na Figura 3 são evidenciadas algumas variáveis que podem influenciar o desempenho acadêmico dos discentes, considerando corpo discente, a instituição e o corpo docente.

\begin{tabular}{|c|l|}
\hline Categorias & \multicolumn{1}{|c|}{ Variáveis levantadas na literatura } \\
\hline Corpo discente & $\begin{array}{l}\text { Bases familiares, background do aluno, as características individuais e a comunidade na } \\
\text { qual o aluno está inserido. Considerando base familiar como: escolaridade dos pais (muito } \\
\text { significativa e positiva), nível de renda da família (significativa e positiva) e existência de } \\
\text { livros em casa (significativa e positiva). }\end{array}$ \\
Instituição & $\begin{array}{l}\text { Recursos tecnológicos, infraestrutura das salas de aula, recursos didáticos, instalações, ma- } \\
\text { teriais disponibilizados aos discentes. } \\
\text { Titulação, formação pedagógica, vínculo com o mercado de trabalho (experiência profis- } \\
\text { sional), regime de trabalho, dentre outras. }\end{array}$ \\
\hline
\end{tabular}

Figura 3. Categorias e variáveis que influenciam o desempenho acadêmico

Fonte: Miranda et al. (2015)

De modo complementar, outros elementos determinantes acabam por influenciar o desempenho acadêmico nos cursos da área de negócio. De acordo com um estudo realizado por Ramos e Carvalho (2009), as representações sociais (interpretação de uma realidade) têm um papel importante no desempenho em disciplinas como matemática e métodos quantitativos. Essa pesquisa foi desenvolvida por meio da aplicação de questionários aos discentes de diversos cursos de uma universidade portuguesa, onde obteve-se uma amostra de 1.269 respondentes. As autoras conseguiram identificar que as representações sociais se relacionam com a autoconfiança e com a percepção de utilidade das disciplinas para o futuro profissional, observando ainda que discentes com maiores níveis de autoconfiança e de percepção da utilidade das disciplinas apresentaram melhores resultados em relação ao desempenho acadêmico.

Os determinantes do desempenho podem ser segregados considerando variáveis de ordem demográficas (gênero, idade, status socioeconômico, raça ou cor, escolaridade dos pais, estado civil e filhos), ordem acadêmica (absenteísmo, desempenho escolar anterior, conhecimento prévio do conteúdo e área de especialização do discente), uso do tempo (emprego, horas de trabalho, horas de estudo e horas de sono), ordem comportamental (motivação, aptidão para a área, nível de ansiedade e tipo de aprendizagem) (Miranda et al., 2015).

O desempenho acadêmico também pode ser influenciado por variáveis de natureza cognitiva, dentre as quais estão autoeficácia, otimismo, autoestima e lócus de controle externo (Mamede, Marques, Rogers \& Miranda, 2015). Os resultados dessa pesquisa evidenciaram a relação estatisticamente significativa do constructo lócus de controle externo com o desempenho discente. Por outro lado, não foi possível identificar que a autoeficácia, o otimismo, o lócus de controle interno, a alta autoestima e a baixa autoestima estão relacionados ao desempenho acadêmico de discente do curso de Ciências Contábeis estudado.

Além das variáveis já apresentadas, o desempenho dos discentes pode estar relacionado ao interesse acadêmico e a motivação. A pesquisa de Fallan e Opstad (2014) encontrou existência de influência positiva e significativa do interesse acadêmico no desempenho de discentes de contabilidade gerencial noruegueses. Para tanto, os resultados da pesquisa evidenciaram que os docentes precisam aumentar o interesse dos discentes pelos conteúdos apresentados.

Ao considerar a motivação, Everaert, Opdecam e Maussen (2017) realizaram uma pesquisa com discentes do Programa de Economia e Administração de Empresas da Universidade de Ghent, na Bélgica. Os resultados dessa pesquisa evidenciaram que as motivações intrínseca e extrínseca podem influenciar na aprendizagem profunda dos discentes, que por sua vez leva ao desempenho acadêmico superior.

\section{PROCEDIMENTOS METODOLÓGICOS}

\subsection{Estratégia de Pesquisa e Definição da População e Amostra}

Quanto as estratégias de pesquisa, foram utilizadas a pesquisa bibliográfica, por meio de estudo de materiais já publicados, como livros e periódicos, pesquisa documental, com a análise do Projeto Político Pedagógico do Curso e das ementas das disciplinas objetos de análise. Além disso, foi adotada a estratégia de levantamento, com a utilização de questionários aos discentes, matriculados no curso de Ciências Contábeis da Universidade Federal de Uberlândia, campus Pontal.

O curso de Ciências Contábeis do Pontal apresentava, no primeiro semestre de 2017, 123 discentes matriculados, conforme dados fornecidos pela coordenação. Assim, o retorno das respostas representa $61 \%$ de toda a população. Vale destacar que não foram aplicados questionários aos discentes matriculados no $1^{\circ}$ período do curso, uma vez que ainda não haviam concluído nenhuma das disciplinas no momento da coleta de dados. A aplicação do questionário foi realizada durante o mês de julho de 2017 , sendo obtidas 75 respostas.

Das 75 respostas obtidas, foram consideradas válidas 72 para análise daqueles que responderam sobre a disciplina de Matemática, 73 para os respondentes da disciplina de Estatística e 74 para os respondentes de Métodos Quantitativos. 
Foi possível 24 reprovações na disciplina de Matemática, 29 na disciplina de Estatística e 26 em Métodos Quantitativos. Pondera-se que um mesmo aluno pode ter obtido reprovação em mais de uma das disciplinas analisadas.

\subsection{Instrumento de Coleta de Dados}

O questionário aplicado foi segregado em três blocos. O primeiro bloco objetivou a caracterização dos respondentes, considerando as variáveis: gênero, idade, estado civil e jornada de trabalho. Já o segundo bloco teve o propósito de identificar elementos relacionados ao desempenho acadêmico dos discentes nas três disciplinas (Matemática, Estatística e Métodos Quantitativos). Vale ressaltar que tais questões apenas foram respondidas pelos discentes que não obtiveram bom desempenho em pelo menos uma das disciplinas e tomaram por referência as possíveis causas de reprovação mencionadas pela literatura. As variáveis são descritas na Figura 4.

\begin{tabular}{|c|c|c|}
\hline Variável & Proxy & Fator relacionado \\
\hline Desempenho do discente & $\begin{array}{l}\text { Considerou-se: "0" como indicativo de aprovação e "1" a } \\
\text { reprovação. }\end{array}$ & Variável dependente \\
\hline Gênero do discente & $\begin{array}{l}\text { Considerou-se: "1" para os discentes do gênero masculino } \\
\text { e "2" para aqueles do gênero feminino. }\end{array}$ & $\begin{array}{c}\text { Característica } \\
\text { individual (variável independente) }\end{array}$ \\
\hline Idade do discente & $\begin{array}{l}\text { Considerou-se: "1" para os discentes que estavam na faixa } \\
\text { etária de } 21 \text { a } 25 \text { anos; "2" para os que tinham entre } 26 \\
\text { e } 30 \text { anos; "3" para os que tinham entre } 31 \text { e } 35 \text { anos; " } 3 \text { " } \\
\text { para os que tinham entre } 36 \text { e } 40 \text { anos; " } 5 \text { " para os que tin- } \\
\text { ham entre } 41 \text { e } 45 \text { anos; "6" para os que tinham entre } 46 \text { e } \\
50 \text { anos e "7" para os que tinham mais de } 50 \text { anos }\end{array}$ & $\begin{array}{c}\text { Característica } \\
\text { individual (variável independente) }\end{array}$ \\
\hline Estado civil & $\begin{array}{l}\text { Considerou-se: "1" para discentes solteiros; " } 2 \text { " para aque- } \\
\text { les que são casados; "3" para os divorciados e " } 4 \text { " para os } \\
\text { viúvos }\end{array}$ & $\begin{array}{c}\text { Característica } \\
\text { individual (variável independente) }\end{array}$ \\
\hline Jornada de Trabalho & $\begin{array}{l}\text { Considerou-se: "1" para discentes que trabalhavam } 44 \\
\text { horas semanais; "2" para os que trabalham entre } 20 \text { e } 44 \\
\text { horas; " } 3 \text { " para os que trabalham até } 20 \text { horas; " } 4 \text { " para os } \\
\text { que trabalham eventualmente e " } 5 \text { " para os que não tra- } \\
\text { balham }\end{array}$ & $\begin{array}{c}\text { Característica } \\
\text { individual (variável independente) }\end{array}$ \\
\hline Frequência nas aulas & $\begin{array}{l}\text { Considerou-se a média de notas de } 0 \text { a } 10 \text { atribuídas pelos } \\
\text { discentes. }\end{array}$ & $\begin{array}{l}\text { Elementos que impactam o desem- } \\
\text { penho (variável independente) }\end{array}$ \\
\hline Participação nas aulas & $\begin{array}{l}\text { Considerou-se a média de notas de } 0 \text { a } 10 \text { atribuídas pelos } \\
\text { discentes. }\end{array}$ & $\begin{array}{l}\text { Elementos que impactam o desem- } \\
\text { penho (variável independente) }\end{array}$ \\
\hline Interesse na disciplina & $\begin{array}{l}\text { Considerou-se a média de notas de } 0 \text { a } 10 \text { atribuídas pelos } \\
\text { discentes. }\end{array}$ & $\begin{array}{l}\text { Elementos que impactam o desem- } \\
\text { penho (variável independente) }\end{array}$ \\
\hline $\begin{array}{l}\text { Tempo dedicado ao estudo } \\
\text { extraclasse }\end{array}$ & $\begin{array}{l}\text { Considerou-se a média de notas de } 0 \text { a } 10 \text { atribuídas pelos } \\
\text { discentes. }\end{array}$ & $\begin{array}{l}\text { Elementos que impactam o desem- } \\
\text { penho (variável independente) }\end{array}$ \\
\hline
\end{tabular}

Figura 4. Variáveis do estudo

Fonte: Elaborada pelas autoras.

Ressalta-se que as assertivas do segundo foram elaboradas considerando as premissas do estudo desenvolvido por Amaro (2014). 


\subsection{Procedimentos de Análise}

A análise dos dados foi desenvolvida por meio da técnica de Regressão Logística. Esse tipo de regressão é utilizado quando se estuda um fenômeno na forma qualitativa, devendo então ser apresentado por uma ou mais variáveis do tipo dummy (Fávero \& Belfiore, 2017). Neste estudo, foi utilizado o software Stata para estimar os cálculos e testes estatísticos e o modelo de regressão logit. O modelo de regressão logit testado foi:

Des $_{i}=\alpha_{0}+\beta_{1}$ Genero $_{i}+\beta_{2}$ Idade $_{i}+\beta_{3}$ EstadoCivil $_{i}+\beta_{4}$ Jornadatrabalho $_{i}+\beta_{5}$ Frequência $_{i}+\beta_{6}$ Participação $_{i}+\beta_{7}$ Interesse $_{i}+$ $\beta_{8}$ Dedicação $_{i}+\varepsilon_{i}$

Em que:

Desi $=$ desempenho do discente

$\alpha 0=$ intercepto

$\beta 1$ Generoi $=$ gênero do discente

$\beta$ Idadei $=$ idade do discente

$\beta 3$ EstadoCivili $=$ estado civil do discente

$\beta 4$ Jornadatrabalhoi $=$ jornada de trabalho do discente

$\beta 5$ Frequênciai $=$ Frequência nas aulas

$\beta 6$ Participaçãoi $=$ Participação nas aulas

$\beta$ 7Interessei $=$ Interesse na disciplina

$\beta 8$ Dedicaçãoi $=$ Tempo dedicado ao estudo extraclasse

$\varepsilon i=$ termo de erro

Pondera-se que a caracterização dos respondentes foi realizada considerando o perfil daqueles que obtiveram reprovação em cada uma das disciplinas analisadas de forma segregada, ou seja, dos discentes que foram reprovados em Matemática, Estatística e Métodos Quantitativos.

\section{ANÁLISE E DISCUSSÃO DOS RESULTADOS}

\subsection{Análise das disciplinas de Matemática, Estatística e Métodos Quantitativos no curso de Ciências Contábeis da FACIP/UFU}

O Curso de Graduação em Ciências Contábeis, iniciou-se em 2007 junto ao início das atividades da Faculdade de Ciências Integradas do Pontal FACIP/UFU. Com duração de 5 anos, o curso disponibiliza anualmente 40 vagas, oferecidas no turno noturno dentro de um regime acadêmico semestral. Os formados neste curso obtêm o título de Bacharel em Ciências Contábeis.

O objetivo do Curso, de acordo com seu Projeto Pedagógico (2007, p. 15), é "formar diplomados na área de contabilidade, legalmente habilitados para o exercício profissional nas diversas instituições que permeiam o convívio social onde seja requerida a presença de um contador".

Na proposta curricular do curso, existem disciplinas que pertencem ao núcleo de formação básica, núcleo de formação profissional e núcleo de formação teórico-prática. Dentre as disciplinas de formação básica, esta pesquisa destaca a presença de Matemática, Estatística e Métodos Quantitativos, ministradas nos $1^{\circ}, 2^{\circ}$ e $3^{\circ}$ períodos, respectivamente, no curso de Ciências Contábeis da FACIP/UFU. Cada uma dessas disciplinas possui uma carga horária de 60h, no regime obrigatório.

A disciplina Matemática, ofertada no $1^{\circ}$ período letivo do curso, contempla em sua ementa os seguintes tópicos: Matrizes e soluções de sistemas lineares; Funções; Limites; Derivadas; Diferencial e Integral. No $2^{\circ}$ período, é ministrada a disciplina de Estatística compreendendo os tópicos: Análise de dados; Distribuição de frequência; Descrição de dados; Representação gráfica; Probabilidades e Teoria de amostragem.

Na sequência, no $3^{\circ}$ período, a disciplina de Métodos Quantitativos apresenta os conteúdos: Introdução sobre conceitos básicos e importância da análise empírica para contadores, administradores e economistas; O modelo de regressão simples; O modelo de regressão múltipla; Regressão múltipla sobre variáveis binárias (dummies); heterocedasticidade, auto correlação serial e multicolinearidade e Noções de análise de séries temporais.

\subsection{Caracterização dos Respondentes}

Essa unidade destina-se a apresentação dos dados relativos à caracterização dos respondentes quanto ao gênero, faixa etária, estado civil, jornada de trabalho, segregados considerando a aprovação/reprovação em cada uma das disciplinas observadas. 
Tabela 1. Caracterização dos Respondentes

\begin{tabular}{|c|c|c|c|c|c|c|c|c|c|c|c|c|}
\hline \multirow[b]{3}{*}{ Feminino } & \multicolumn{4}{|c|}{$\begin{array}{l}\text { Matemática } \\
\qquad(n=72)\end{array}$} & \multicolumn{4}{|c|}{$\begin{array}{c}\text { Estatistica } \\
(n=73)\end{array}$} & \multicolumn{4}{|c|}{$\begin{array}{l}\text { Métodos Quantitativos } \\
\qquad(\mathrm{n}=74)\end{array}$} \\
\hline & \multicolumn{2}{|c|}{ Reprovado } & \multicolumn{2}{|c|}{ Aprovado } & \multicolumn{2}{|c|}{ Reprovado } & \multicolumn{2}{|c|}{ Aprovado } & \multicolumn{2}{|c|}{ Reprovado } & \multicolumn{2}{|c|}{ Aprovado } \\
\hline & 9 & $13 \%$ & 29 & $40 \%$ & 11 & $15 \%$ & 27 & $37 \%$ & 11 & $15 \%$ & 29 & $39 \%$ \\
\hline Masculino & 15 & $21 \%$ & 19 & $26 \%$ & 18 & $25 \%$ & 17 & $23 \%$ & 15 & $20 \%$ & 19 & $26 \%$ \\
\hline 21-25 anos & 8 & $11 \%$ & 26 & $36 \%$ & 8 & $11 \%$ & 26 & $36 \%$ & 8 & $11 \%$ & 26 & $35 \%$ \\
\hline 26-30 anos & 11 & $15 \%$ & 12 & $17 \%$ & 14 & $19 \%$ & 10 & $14 \%$ & 10 & $14 \%$ & 14 & $19 \%$ \\
\hline 31-35 anos & 4 & $6 \%$ & 5 & $7 \%$ & 5 & $7 \%$ & 4 & $5 \%$ & 4 & $5 \%$ & 5 & $7 \%$ \\
\hline $36-40$ anos & 1 & $1 \%$ & 2 & $3 \%$ & 2 & $3 \%$ & 1 & $1 \%$ & 2 & $3 \%$ & 1 & $1 \%$ \\
\hline $41-45$ anos & 0 & $0 \%$ & 2 & $3 \%$ & 0 & $0 \%$ & 2 & $3 \%$ & 0 & $0 \%$ & 2 & $3 \%$ \\
\hline $46-50$ anos & 0 & $0 \%$ & 0 & $0 \%$ & 0 & $0 \%$ & 0 & $0 \%$ & 1 & $1 \%$ & 0 & $0 \%$ \\
\hline Mais de 50 anos & 0 & $0 \%$ & 1 & $1 \%$ & 0 & $0 \%$ & 1 & $1 \%$ & 1 & $1 \%$ & 0 & $0 \%$ \\
\hline Solteiro & 23 & $32 \%$ & 41 & $57 \%$ & 28 & $38 \%$ & 37 & $51 \%$ & 23 & $31 \%$ & 42 & $57 \%$ \\
\hline Casado & 1 & $1 \%$ & 6 & $8 \%$ & 1 & $1 \%$ & 6 & $8 \%$ & 3 & $4 \%$ & 5 & $7 \%$ \\
\hline Divorciado & 0 & $0 \%$ & 1 & $1 \%$ & 0 & $0 \%$ & 1 & $1 \%$ & 0 & $0 \%$ & 1 & $1 \%$ \\
\hline Viúvo & 0 & $0 \%$ & 0 & $0 \%$ & 0 & $0 \%$ & 0 & $0 \%$ & 0 & $0 \%$ & 0 & $0 \%$ \\
\hline 44 horas & 14 & $19 \%$ & 17 & $24 \%$ & 17 & $23 \%$ & 14 & $19 \%$ & 16 & $22 \%$ & 17 & $23 \%$ \\
\hline 20 a 44 horas & 7 & $10 \%$ & 15 & $21 \%$ & 6 & $8 \%$ & 16 & $22 \%$ & 6 & $8 \%$ & 16 & $22 \%$ \\
\hline até 20 horas & 1 & $1 \%$ & 2 & $3 \%$ & 1 & $1 \%$ & 2 & $3 \%$ & 1 & $1 \%$ & 2 & $3 \%$ \\
\hline Trabalho eventual & 0 & $0 \%$ & 0 & $0 \%$ & 0 & $0 \%$ & 0 & $0 \%$ & 0 & $0 \%$ & 0 & $0 \%$ \\
\hline Não trabalha & 2 & $3 \%$ & 14 & $19 \%$ & 5 & $7 \%$ & 12 & $16 \%$ & 3 & $4 \%$ & 13 & $18 \%$ \\
\hline
\end{tabular}

Fonte: Dados da Pesquisa

Como pode-se observar ao verificar a Tabela 1, o número de discentes que obtiveram aprovação é superior aos que foram reprovados, seja ao considerar a disciplina de Matemática, Estatística ou Métodos Quantitativos. Destaca-se o fato da maioria dos aprovados se considerarem como pertencentes ao gênero feminino, com uma representatividade de $40 \%$ quando se observa a disciplina de Matemática, 37\% na disciplina de Estatística e 39\% na disciplina de Métodos Quantitativos.

Ao observar a idade dos discentes respondentes, pode-se observar que existe uma concentração de indivíduos que estão nas faixas que compreendem aqueles que tem entre 21 e 30 anos. Destaca-se que a maior parte dos reprovados estão concentrados na faixa etária que compreende os discentes dos 26 aos 30 anos. Na disciplina de Estatística, por exemplo, o índice de reprovados é de 19\% para os discentes que estão na faixa etária dos 26 aos 30 anos, enquanto que os aprovados representam 14\% para aqueles indivíduos que estão nessa mesma faixa etária. Ao considerar as disciplinas de Matemática e Métodos Quantitativos, tem-se que o percentual de discentes aprovados é superior ao de reprovados, considerando ainda a faixa etária que compreende discentes que tem entre 26 e 30 anos.

Quanto ao estado civil dos respondentes, pode-se averiguar que a maior parte dos discentes é solteira e obteve aprovação nas disciplinas de Matemática, Estatística e Métodos Quantitativos. Para as disciplinas de Matemática e Métodos Quantitativos houve um total de $57 \%$ de aprovados e para a disciplina de Estatística os aprovados representam $51 \%$.

Por fim, os números indicam que o fato de o discente trabalhar acaba por impactar em sua aprovação/reprovação. Destaca-se que o maior percentual de reprovação acontece quando os discentes trabalham, principalmente quando exercem atividades que ocupam 44 horas semanais. Nesse caso, os percentuais de reprovação representam $19 \%, 23 \%$ e 22\% para as disciplinas de Matemática, Estatística e Métodos Quantitativos, respectivamente. Por outro lado, o percentual de reprovação é menor quando os discentes não trabalham, com valores que indicam 3\%, 7\% e 4\%, ao observar as disciplinas de Matemática, Estatística e Métodos Quantitativos, respectivamente.

Em suma, pode-se perceber que os maiores quantitativos de reprovação estão quando se analisa a disciplina de Estatística, seja quando se observa o gênero, a idade, o estado civil ou a carga horária de trabalho do discente. 


\subsection{Análise dos Fatores Relacionados ao Desempenho Acadêmico nas disciplinas de Matemática, Estatística e Métodos Quantitativos}

Sobre a percepção dos discentes quanto ao seu desempenho nas disciplinas, foram apresentados 4 pontos para avaliação, onde solicitou-se a atribuição de notas de 0 a 10. Os dados obtidos, por meio de cálculo de média, podem ser verificados na Tabela 2.

Tabela 2. Percepção do Desempenho pelo Discente

\begin{tabular}{|l|c|c|c|}
\hline \multicolumn{1}{|c|}{ Descrição } & Matemática & Estatística & $\begin{array}{c}\text { Métodos } \\
\text { Quantitativos }\end{array}$ \\
\cline { 2 - 4 } & Média & Média & Média \\
\hline Frequência nas aulas & 8,92 & 8,74 & 8,66 \\
Participação nas aulas & 7,67 & 7,73 & 7,59 \\
Interesse na disciplina & 6,79 & 6,73 & 6,85 \\
Tempo dedicado ao estudo extraclasse & 6,21 & 6,14 & 6,31 \\
\hline
\end{tabular}

Fonte: Dados da Pesquisa

No geral, percebe-se que os alunos atribuem seu desempenho, principalmente, ao fato de serem frequentes, seguido pelo fato de participarem nas aulas, atribuindo pouco peso à questão do tempo de dedicação aos estudos extraclasse.

A Tabela 3 evidencia sobre os valores da Regressão Logística considerando a análise do desempenho na disciplina de Matemática.

Tabela 3. Regressão Logística para desempenho na disciplina de Matemática

\begin{tabular}{|c|c|c|c|c|}
\hline & Estimativa & Erro padrão & Valor z & $\operatorname{Pr}(>|z|)$ \\
\hline Intercepto & 8.75051 & 3.06490 & 2.855 & $0.0043 * \star$ \\
\hline Gênero (masculino) & 0.28907 & 1.00347 & 0.288 & 0.7733 \\
\hline Faixa etária (entre 26 e 30 anos) & 1.36873 & 0.87220 & 1.569 & 0.1166 \\
\hline Faixa etária (entre 31 e 35 anos) & 2.43938 & 1.31190 & 1.859 & 0.0630 \\
\hline Faixa etária (entre 36 e 40 anos) & 0.24750 & 1.46704 & 0.169 & 0.8660 \\
\hline Faixa etária (entre 41 e 45 anos) & -7.65365 & 3956.18178 & -0.002 & 0.9985 \\
\hline Faixa etária (mais de 50 anos) & -12.61408 & 3956.18107 & -0.003 & 0.9975 \\
\hline Estado civil (casado) & -3.94544 & 2.17389 & -1.815 & 0.0695 \\
\hline Estado civil (divorciado) & -6.54689 & 5594.88455 & -0.001 & 0.9991 \\
\hline Trabalho entre 20 e 44 horas & -1.37522 & 1.15111 & -1.195 & 0.2322 \\
\hline Trabalho até 20 horas & -0.01182 & 2.95222 & -0.004 & 0.9968 \\
\hline Não trabalho & -3.11779 & 1.46115 & -2.134 & $0.0329 *$ \\
\hline Frequência nas aulas & -0.25459 & 0.30552 & -0.833 & 0.4047 \\
\hline Participação nas aulas & -0.80201 & 0.36574 & -2.193 & 0.0283 * \\
\hline Interesse pela disciplina & 0.19723 & 0.18417 & 1.071 & 0.2842 \\
\hline Dedicação aos estudos & -0.40125 & 0.19655 & -2.041 & 0.0412 * \\
\hline
\end{tabular}

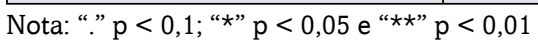

Fonte: Dados da pesquisa 
Como pode ser observado, ao nível de $10 \%$ de significância, existem evidencias de que os respondentes que estão na faixa etária que compreende dos 31 aos 35 anos, possuem maior probabilidade de reprovação em relação aos que estão entre 21 e 25 anos, considerados como base. Ainda considerando 10\% de significância, percebe-se que os respondentes casados, possuem menor chance de reprovação na disciplina de Matemática em relação aos solteiros.

Nota-se ainda que existem evidencias estatísticas, considerando o nível de $5 \%$ de significância, de que aqueles respondentes que não trabalham, bem como aqueles que atribuíram seu desempenho ao fato de participarem das aulas e dedicarem tempo para estudos extraclasse, apresentam menor chance de reprovação, tendo por base a relação negativa com a variável de desempenho.

A Tabela 4 evidencia sobre os valores da Regressão Logística considerando a análise do desempenho na disciplina de Estatística.

Tabela 4. Regressão Logística para desempenho na disciplina de Estatística

\begin{tabular}{|c|c|c|c|c|}
\hline & Estimativa & Erro padrão & Valor z & $\operatorname{Pr}(>|z|)$ \\
\hline Intercepto & 24.0782 & 9.2936 & 2.591 & $0.00957 * *$ \\
\hline Gênero (masculino) & 1.6986 & 1.4215 & 1.195 & 0.23210 \\
\hline Faixa etária (entre 26 e 30 anos) & 5.2736 & 2.0228 & 2.607 & $0.00913 * *$ \\
\hline Faixa etária (entre 31 e 35 anos) & 5.7109 & 2.1596 & 2.644 & 0.00818 ** \\
\hline Faixa etária (entre 36 e 40 anos) & 3.4262 & 1.8010 & 1.902 & 0.05711 \\
\hline Faixa etária (entre 41 e 45 anos) & -0.4445 & 3956.1855 & 0.000 & 0.99991 \\
\hline Faixa etária (mais de 50 anos) & -5.4190 & 3956.1835 & -0.001 & 0.99891 \\
\hline Estado civil (casado) & -6.4653 & 3.6636 & -1.765 & 0.07761 \\
\hline Estado civil (divorciado) & -11.2875 & 5594.8859 & -0.002 & 0.99839 \\
\hline Trabalho entre 20 e 44 horas & -6.5319 & 2.5216 & -2.590 & $0.00959 * *$ \\
\hline Trabalho até 20 horas & -0.2543 & 12.0153 & -0.021 & 0.98312 \\
\hline Não trabalho & -5.0577 & 2.2105 & -2.288 & 0.02214 * \\
\hline Frequência nas aulas & -1.2581 & 0.5989 & -2.101 & 0.03566 * \\
\hline Participação nas aulas & -1.2413 & 0.5099 & -2.434 & 0.01492 * \\
\hline Interesse pela disciplina & 0.1243 & 0.2206 & 0.563 & 0.57317 \\
\hline Dedicação aos estudos & -0.8288 & 0.3500 & -2.368 & 0.01787 * \\
\hline
\end{tabular}

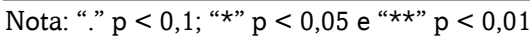

Fonte: Dados da pesquisa

Ao analisar a Tabela 4, pode-se observar que existem evidencias de que os respondentes que estão nas faixas etárias que compreendem indivíduos que têm entre 26 e 35 anos, possuem maior probabilidade de reprovação em relação aos que estão entre 21 e 25 anos, considerados como base, ao nível de $1 \%$ de significância.

Existem evidencias estatísticas, considerando o nível de 5\% de significância, de que aqueles respondentes que não trabalham, bem como aqueles que atribuíram seu desempenho ao fato de serem frequentes, participarem das aulas e dedicarem tempo para estudos extraclasse, apresentam menor chance de reprovação, tendo por base a relação negativa com a variável de desempenho. Na mesma linha, observa-se que os discentes que trabalham entre 20 e 44 horas semanais, também apresentam menor chance de reprovação, considerando o nível de significância de 1\%. Ao nível 10\% de significância, percebe-se que os respondentes casados, também possuem menor chance de reprovação na disciplina de Estatística em relação aos solteiros.

A Tabela 5 evidencia sobre os valores da Regressão Logística considerando a análise do desempenho na disciplina de Métodos Quantitativos. 
Tabela 5. Regressão Logística para desempenho na disciplina de Métodos Quantitativos

\begin{tabular}{|c|c|c|c|c|}
\hline & Estimativa & Erro padrão & Valor z & $\operatorname{Pr}(>|z|)$ \\
\hline Intercepto & 7.0995 & 2.3026 & 3.083 & $0.00205 * *$ \\
\hline Gênero (masculino) & 1.2816 & 0.8876 & 1.444 & 0.14880 \\
\hline Faixa etária (entre 26 e 30 anos) & 1.8619 & 0.9968 & 1.868 & 0.06177 \\
\hline Faixa etária (entre 31 e 35 anos) & 3.3312 & 1.4513 & 2.295 & 0.02172 * \\
\hline Faixa etária (entre 36 e 40 anos) & 3.1601 & 1.5769 & 2.004 & 0.04507 * \\
\hline Faixa etária (entre 41 e 45 anos) & -9.2016 & 3956.1813 & -0.002 & 0.99814 \\
\hline Faixa etária (entre 46 e 50 anos) & 17.4165 & 3956.1807 & 0.004 & 0.99649 \\
\hline Faixa etária (mais de 50 anos) & 21.6972 & 3956.1808 & 0.005 & 0.99562 \\
\hline Estado civil (casado) & -2.7946 & 1.7537 & -1.594 & 0.11105 \\
\hline Estado civil (divorciado) & -5.7652 & 5594.8844 & -0.001 & 0.99918 \\
\hline Trabalho entre 20 e 44 horas & -1.4170 & 0.9938 & -1.426 & 0.15390 \\
\hline Trabalho até 20 horas & 1.2286 & 2.0109 & 0.611 & 0.54122 \\
\hline Não trabalho & -2.9517 & 1.3024 & -2.266 & 0.02342 * \\
\hline Frequência nas aulas & -1.0820 & 0.3943 & -2.744 & $0.00607 * *$ \\
\hline Participação nas aulas & 0.2231 & 0.3169 & 0.704 & 0.48144 \\
\hline Interesse pela disciplina & 0.1503 & 0.2116 & 0.710 & 0.47749 \\
\hline Dedicação aos estudos & -0.3545 & 0.1675 & -2.116 & 0.03433 * \\
\hline
\end{tabular}

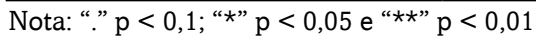

Fonte: Dados da pesquisa

Como pode ser observa na Tabela 5, existem evidências de que os respondentes que estão nas faixas etárias que compreendem indivíduos que têm entre 31 e 40 anos, possuem maior probabilidade de reprovação em relação aos que têm entre 21 e 25 anos, considerados como base, ao nível de 5\% de significância. Considerando 10\% de significância, percebe-se que os respondentes que estão na faixa que compreende indivíduos que têm entre 26 e 30 anos também possuem maior probabilidade de reprovação. No caso da disciplina de Métodos Quantitativos, não foram apresentadas evidências estatisticamente significativas de que o estado civil impacta no desempenho.

Existem evidencias estatísticas, considerando o nível de $5 \%$ de significância, de que aqueles respondentes que não trabalham, bem como aqueles que atribuíram seu desempenho ao fato de dedicarem tempo para estudos extraclasse, apresentam menor chance de reprovação, tendo por base a relação negativa com a variável de desempenho. Observa-se ainda que os discentes que possuem frequência nas aulas, também apresentam menor chance de reprovação, considerando o nível de significância de $1 \%$.

\subsection{Discussão dos Resultados}

Essa seção destina-se a discussão geral em relação aos achados do presente estudo em comparação a outros que abordaram sobre o desempenho acadêmico em cursos de graduação. Considerando a amostra analisada, a variável gênero, bem como a variável que compreende a auto avaliação em relação ao interesse pela disciplina não demonstraram significância estatística em relação à variável que designava o desempenho acadêmico nas disciplinas de Matemática, Estatística e Métodos Quantitativos.

O achado da pesquisa em relação ao gênero diverge com o que foi observado em pesquisas como a de Cornachione Junior, Cunha, Luca e Ott (2010), já que não foi observada influência estatisticamente significativa do gênero em relação ao desempenho acadêmico. A pesquisa de Cornachione Junior et al. (2010), apresentou evidências da existência de relação significante entre gênero e desempenho, mesmo que somente quando considerado o desempenho acadêmico superior. Discentes do gênero feminino atribuíram seu desempenho superior ao seu esforço próprio, em maior nível que aqueles do gênero masculino.

Algumas pesquisas evidenciaram que o desempenho de discentes do gênero feminino é superior ao obtido por aqueles do gênero masculino (Duckworth \& Seligman, 2006; Miranda, Mamede, Marques \& Rogers, 2014), considerando que tendem a ter maior autocontrole e autodisciplina (Duckworth \& Seligman, 2006). Todavia, pesquisas como a desenvolvida por Masasi (2012) demonstraram que discentes do gênero masculino apresentam melhores resultados.

Além do gênero outras variáveis são consideradas ao se observar a relação com o desempenho acadêmico. Santos (2012), desenvolveu uma pesquisa junto à discentes concluintes de Ciências Contábeis. Por meio dessa pesquisa, o autor identificou a existência de relação significativa entre o desempenho acadêmico e características como horas de dedicação aos estudos, faixa de renda familiar, ter estudado o ensino médio em escolas públicas e ter tido professores com domínio de conteúdo e que ministravam aulas predominantemente expositivas. 
Ao considerar a questão da idade, os resultados da pesquisa desenvolvida por Araújo et al. (2013), levaram a concluir que discentes mais velhos tendem a ter aumento no desempenho final. Na mesma linha, Miranda et al. (2014) observaram que discentes com faixa etária entre 20 e 40 anos apresentaram rendimento inferior em comparação aos que estão em outras faixas etárias, tais como aqueles que possuem mais de 40 anos. A presente pesquisa observou que os discentes que estavam na faixa etária entre 26 e 40 anos, apresentaram maior chance para reprovação, corroborando com os achados das pesquisas realizadas ao apresentar que discentes mais jovens tendem a apresentar menor desempenho. Tal achado pode ser relacionado ao fato de que os discentes mais velhos tendem a ser mais motivados e disciplinados do que aqueles mais novos (Van Wyk, 2011).

Em relação ao estado civil, apresente pesquisa observou que o fato do discente ser casado tem influência no desempenho, de modo que aqueles indivíduos casados apresentam menor chance de reprovação em comparação aos solteiros, isso quando da observação das disciplinas de Matemática e Estatística. Por outro lado, não foi observada relação estatisticamente significativa entre estado civil e desempenho ao se analisar os respondentes da disciplina de Métodos Quantitativos, indo ao encontro do apresentado por Masasi (2012) e Miranda et al. (2014).

A conciliação entre estudo e trabalho tem sido um determinante observado nas pesquisas que buscam compreender o desempenho acadêmico. Cavichioli, Santos e Silva (2016) realizaram uma pesquisa considerando a relação de variáveis comportamentais com o desempenho acadêmico. Dentre os resultados, verificou-se que a conciliação entre estudo e trabalho impacta de forma negativa no desempenho. Nesse sentido, a presente pesquisa evidenciou que aqueles indivíduos que trabalham possuem maior chance de reprovação do que aqueles que não trabalham, principalmente quando se considera aqueles que possuem cargas mais altas de jornada de trabalho.

A presente pesquisa observou ainda que discentes que manifestaram que são frequentes e participam das aulas, bem como aqueles que dedicam tempo para estudo extraclasse, acabam por apresentar menor chance de reprovação. Como constado por Amaro e Beuren (2018), o desempenho acadêmico pode ser influenciado, dentre outros fatores, pela quantidade de horas que os discentes dedicam ao estudo extraclasse. Ressalta-se que as pesquisas observam que os discentes que são mais dedicados aos estudos acabam por apresentar melhor desempenho acadêmico (Andrietti \& Velasco, 2015; Rodrigues et al., 2016; Martins \& Marinho, 2019).

Em suma, pode-se perceber que os resultados da pesquisa contribuem de maneira substancial aos estudos já realizados e que abordam sobre desempenho acadêmico ao reforçar os resultados por esses obtidos. Pondera-se que a presente pesquisa acrescenta ao observar o desempenho nas disciplinas de Matemática, Estatística e Métodos Quantitativos, uma vez que os estudos aqui considerados acabam por verificar o desempenho em cursos da área de negócios de forma geral, sem especificar disciplinas.

\section{CONSIDERAÇÕES FINAIS}

A presente pesquisa teve por propósito identificar a relação dos fatores relacionados às características individuais e atitudes no desempenho acadêmico nas disciplinas de Matemática, Estatística e Métodos Quantitativos, ministradas no curso de Ciências Contábeis da Universidade Federal de Uberlândia, campus Pontal.

Os resultados da Regressão Logística evidenciaram significância estatística que comprovam que os discentes que estão nas faixas etárias que compreende dos 26 aos 40 anos, possuem maior probabilidade de reprovação. Por outro lado, percebeu-se que discentes que não trabalham ou possuem uma menor jornada de trabalho, bem como aqueles que atribuíram seu desempenho ao fato de serem frequentes, participarem das aulas e dedicarem tempo para estudos extraclasse, apresentam menor chance de reprovação. A probabilidade de reprovação também é menor para os discentes casados.

Vale ressaltar que as disciplinas de Matemática, Estatística e Métodos Quantitativos são de grande importância na formação do profissional de contabilidade, pois auxiliam a compreensão de dados estatísticos, da contabilidade de custos, dados gerenciais, e para analisar balanços e diversas outras informações do cotidiano profissional (Silva \& Machado, 2004; Limongi et al., 2012; Stringhini, 2014; Alves et al., 2015).

Face aos resultados, recomenda-se que a coordenação e os docentes do curso Ciências Contábeis da Universidade Federal de Uberlândia, campus Pontal, façam a revisão das ementas das disciplinas de Matemática, Estatística e Métodos Quantitativos, juntamente com os docentes que ministram tais disciplinas, na tentativa de reformulação de modo a tornar as disciplinas mais atrativas, considerando as reais necessidades de formação profissional do contador.

A presente pesquisa apresenta algumas limitações, dentre as quais está a amostra da pesquisa. Destaca-se que a coleta foi realizada apenas com estudantes de uma única universidade e de um único curso, assim é importante frisar que os resultados apresentados por este estudo não podem ser generalizados à outras instituições ou cursos. Ademais, pontua-se a limitação em refere ao instrumento de coleta utilizado, que acaba por desconsiderar outras possibilidades em relação aos diferentes determinantes que podem influenciar no desempenho acadêmico.

Como sugestão para estudos futuros, indica-se o aprofundamento das principais questões apontadas pelos discentes como possíveis causas das reprovações, por meio de entrevistas para que se possa mensurar de forma mais precisa os fatores relacionados ao desempenho. Cabe ainda a realização de aplicação do método em outras disciplinas do curso, a fim de obter novos panoramas sobre o desempenho nas diversas disciplinas necessárias à formação do futuro contador. Além disso, sugere-se estudos mais aprofundados, analisando as possíveis justificativas em relação às causas apontadas como aquelas que afetam o desempenho acadêmico. 


\section{REFERÊNCIAS}

Abdullah, A. M. (2011). Fatores que afetam o desempenho de estudantes de negócios na Universidade Árabe Aberta: O caso do Kuwait. International Journal of Business and Management, 6 (5), 146-155.

Alves, F. S., Farias, M. R. S., \& Farias, K. T. R. (2015). Desempenho acadêmico em métodos quantitativos nos cursos de Ciências Contábeis. Enfoque: Reflexão Contábil, 34(2), 37-50.

Al-Twaijry, A. A. (2010). Student academic performance in undergraduate managerial-accounting courses. Journal of Education for Business, 85(6), 311-322.

Amaro, H. D. (2014). Influência de fatores contingenciais no desempenho acadêmico de discentes do curso de ciências contábeis de IFES. Dissertação (Mestrado em Contabilidade), Setor de Ciências Sociais Aplicadas, Universidade Federal do Paraná, Curitiba.

Amaro, H. D., \& Beuren, I. M. (2018). Influência de Fatores Contingenciais no Desempenho Acadêmico de Discentes do Curso de Ciências Contábeis. Revista de Educação e Pesquisa em Contabilidade (REPeC), 12(1), 22-44.

Andrietti, V., \& Velasco, C. (2015). Lecture attendance, study time, and academic performance: A panel data study. The Journal of Economic Education, 46(3), 239-259.

Araújo, E. A. T., Camargos, M. A., Camargos, M. C. S., \& Dias, A. T. (2013). Desempenho Acadêmico de Discentes do Curso de Ciências Contábeis: Uma análise dos seus fatores determinantes em uma IES Privada. Contabilidade Vista \& Revista, 24(1), 60-83.

BRASIL. Resolução CNE/CES 10, de 16 de dezembro de 2004: Institui as Diretrizes Curriculares Nacionais para o Curso de Graduação em Ciências Contábeis, bacharelado, e dá outras providências. 2004. Disponível em: <http://portal.mec.gov.br/cne/arquivos/ pdf/rces10_04.pdf>. Acesso em: 26 fev. 2017.

Boarin, J. J. (2003). As tendências da formação em Ciências Contábeis no Brasil. Contabilidade Vista \& Revista, 14(1), 9-14.

Cardozo, W. (2006). O ensino de métodos quantitativos nos cursos de Ciências Contábeis. Dissertação (Mestrado em Contabilidade) - Programa de Pós-Graduação em Ciências Contábeis, Fundação Instituto Capixaba de Pesquisas em Contabilidade, Economia e Finanças, Vitória.

Cavichioli, D., Santos, K. P., \& Silva, S. C. (2016). Variáveis que influenciam o desempenho acadêmico em um curso de Ciências Contábeis. In: Congresso UNB de Contabilidade e Governança. Recuperado em janeiro 15, 2020 de http://soac.unb.br/index.php/ccgunb/ ccgunb2/paper/viewFile/5212/1403.

Comitê de Pronunciamentos Contábeis - CPC. (2011). Pronunciamento Técnico CPC 00. Estrutura Conceitual para Elaboração e Divulgação de Relatório Contábil-Financeiro, 2011. Brasília: Conselho Federal de Contabilidade. Recuperado em janeiro 15, 2020 de http://www.cpc.org.br/CPC/DocumentosEmitidos/Pronunciamentos/Pronunciamento?Id=80.

Cornachione Junior, E. B., Cunha, J. V. A. D., Luca, M. M. M., \& Ott, E. (2010). O bom é meu, o ruim é seu: perspectivas da teoria da atribuição sobre o desempenho acadêmico de alunos da graduação em Ciências Contábeis. Revista Contabilidade \& Finanças, 21(53), $1-23$

Costa, F. J., Lopes Júnior, E. P., Lemos, A. Q., \& Lôbo, R. J. S. (2009). Uma análise da atitude e do interesse dos estudantes de contabilidade quanto à área de métodos quantitativos. Revista Gestão Organizacional, 2(2), 123-137.

Costa, F. J., Machado, M. A. V., \& Lima Neto, E. A. (2014). Métodos Quantitativos e Desempenho Acadêmico: uma análise com estudantes de administração e contabilidade. Teoria e Prática em Administração (TPA), 4(2), 28-48.

Duckworth, A. L., \& Seligman, M. E. (2006). Self-discipline gives girls the edge: Gender in self-discipline, grades, and achievement test scores. Journal of educational psychology, 98(1), 198.

Everaert, P., Opdecam, E., \& Maussen, S. (2017). The relationship between motivation, learning approaches, academic performance and time spent. Accounting Education, 26(1), 78-107.

Fallan, L., \& Opstad, L. (2014). Beyond gender performance in accounting: does personality distinction matter?. Accounting Education, 23(4), 343-361.

Fávero, L.P., \& Belfiore, P. (2017). Manual de análise de dados: Estatística e modelagem multivariada com Excel®, SPSS® e Stata®. Rio de Janeiro: Elsevier.

Fiorentin, M., \& de Souza Domingues, M. J. C. (2012). Interdisciplinaridade no curso de Ciências Contábeis: um estudo na Universidade de Passo Fundo-RS. ConTexto, 12(21), 7-16.

Imose, R., \& Barber, L. K. (2015). Using undergraduate grade point average as a selection tool: A synthesis of the literature. The Psychologist-Manager Journal, 18(1), 1-11.

Jansen, J., \& Villiers, C. (2016). Determinants of student performance in an accounting degree programme. South African Journal of Accounting Research, 30(1), 1-28. 41-46.

Kumar, G. P. (2018). Variables Impacting Students' Performance in Management Course. SDMIMD Journal of Management, 9,

Limongi, B., Pfitscher, E. D., Freitas, C. L., Krüger, L. M., \& Soares, S. V. (2012). A contribuição das ciências exatas às ciências sociais aplicadas: estudo no curso de ciências contábeis. Revista Iberoamericana de Educación, 59(2), 1-11.

Mamede, S. D. P. N., Marques, A. V. C., Rogers, P., \& Miranda, G. J. (2015). Determinantes psicológicos do desempenho acadêmico em Ciências Contábeis: evidências do Brasil. Brazilian Business Review, 12, 54-75.

Martins, A. M. (2004). Insucesso Académico na Universidade: Causas e Estratégias para a sua Minimização. Docência Universitária-Univesidad Central de Venezuela, 5(1-2), 49-60. 
Martins, Z. B., \& Marinho, S. V. (2019). Relação das variáveis concernentes ao desempenho acadêmico: um estudo com alunos de graduação em ciências contábeis. Revista Universo Contábil, 15(1), 27-48.

Masasi, N. J. (2012). How personal attribute affect students' performance in undergraduate accounting course: A case of adult learner in Tanzania. International Journal of Academic Research in Accounting, Finance and Management Sciences, 2(2), 201-211.

Miranda, G. J., Lemos, K. C. S., Oliveira, A. S., \& Ferreira, M. A. (2015). Determinantes do desempenho acadêmico na área de negócios. Revista Meta: Avaliação, 7(20), 175-209.

Miranda, G. J., Mamede, S. P. N., Marques, A. V. C., \& Rogers, P. (2014). Determinantes do desempenho acadêmico em Ciências Contábeis: uma análise de variáveis comportamentais. In Congresso USP de Controladoria e Contabilidade, XIV. Recuperado em janeiro 15, 2020 de https://congressousp.fipecafi.org/anais/artigos142014/299.pdf.

Munhoz, A. M. H. (2004). Uma análise multidimensional da relação entre inteligência e desempenho acadêmico em universitários ingressantes. Dissertação (Mestrado em Educação) - Faculdade de Educação, Universidade Estadual de Campinas, Campinas.

Ramos, M., \& Carvalho, H. (2009). Os métodos quantitativos no Ensino Superior: uma tipologia de representações. Educação $e$ Pesquisa, 35(1), 15-32.

Rodrigues, B. C. O., Resende, M. S., Miranda, G. J., \& Pereira, J. M. (2016). Determinantes do desempenho acadêmico dos alunos dos cursos de ciências contábeis no ensino a distância. Enfoque: Reflexão Contábil, 35(2), 139-153.

Santos, N. A. (2012). Determinantes do desempenho acadêmico dos alunos dos cursos de ciências contábeis. Tese (Doutorado em Controladoria e Contabilidade) - Departamento de Contabilidade e Atuária da Faculdade de Economia, Administração e Contabilidade da Universidade de São Paulo, FEA/USP, São Paulo.

Seow, P. S., Pan, G., \& Tay, J. (2014). Revisiting the determinants of students' performance in an undergraduate accountancy degree programme in Singapore. Global Perspectives on Accounting Education, 11, 1-23.

Silva, D. N., \& Machado, G. G. (2004). A matemática e a graduação em ciências contábeis. Revista de Contabilidade do Mestrado em Ciências Contábeis da UERJ, 9(1), 33-52.

Silva, V. D., Oliveira, K. D., Rogers, P., \& Miranda, G. J. (2015). Comportamento e desempenho acadêmico no curso de ciências contábeis. In Comunicação apresentada em Congresso ANPCONT. Associação Nacional de Programas de Pós-graduação em Ciências Contábeis. Curitiba, Brasil.

Stringhini, L. F. (2014). A utilização de métodos quantitativos em contabilidade. Contabilidade em Pauta, 3.

United Nations Conference on Trade and Development - UNCTAD. (2003). Revised Model Accounting Curriculum (MC). Recuperado em maio 15, 2019 de http://unctad.org/en/Docs/c2isar21_en.pdf.

Van Wyk, E. (2011). A Note: The SAICA Part I Qualifying examinations: Factors that may influence candidates' success. South African Journal of Accounting Research, 25(1), 145-174. 